\title{
Life: quality, value and justice
}

\section{John Harris}

Centre for Social Ethics and Policy, University of Manchester, Manchester, U.K.

\section{Summary}

The claim is questioned that QALYs (quality adjusted life years) provide an effective measure of beneficial health care and of cost-effective and or efficient health care and allow for a morally defensible way of distributing scarce health resources. It is argued the QALYs: (1) fallaciously value time lived instead of individual lives; (2) take an excessively narrow view of what quality of life might be; and finally and perhaps most importantly (3) they are unjust.

QALYs; Quality of life; Justice

If you or I should need health care we would obviously want the health care that would do us most good. If public resources are to be spent on health care, those responsible have an obligation to get as much beneficial health care for their money as is possible. To find a way of meeting both these objectives simultaneously would be a great achievement and so the claim of the inventors of QALYs (quality adjusted life years) that their measure of health care does just this is of great significance.

Even if this claim can be sustained, the problem of distributing health care resources is not solved, for there may be moral constraints on the ways in which this may legitimately be done. For example, public resources should obviously be distributed in accordance with some defensible principle of justice and in particular no distribution of public resources should discriminate unfairly against identifiable groups of citizens. However, if it could be shown that QALYs provide an effective measure of beneficial health care and of cost-effective or of efficient health care, this would take us much of the way towards a morally defensible way of distributing scarce health care resources.

Address for correspondence: Dr. John Harris, Research Director, Centre for Social Ethics and Policy, University of Manchester, Oxford Road, Manchester M13 9PL, U.K. 
In this short paper [1] I shall try to indicate why QALYs fail on both counts. That is, the extent to which they fail to meet both the objectives mentioned at the outset and why they fail to conform to the minimum standards of justice required for the distribution of public resources.

'The essence of a QALY is that it takes a year of healthy life to be worth 1, but regards a year of unhealthy life expectancy as worth less than $1 \ldots$

The general idea is that a beneficial health care activity is one that generates a positive amount of OALYs, and that an efficient health care activity is one where the cost per QALY is as low as it can be. A high priority activity is one where the cost per QALY is high' [2].

These claims by Alan Williams are strong and if they can be sustained, QALYs will be a formidable tool, for Williams is claiming that they provide a measure of beneficial health care, a measure of efficient health care and a method of ordering priorities in health care.

Basically there is one thing right about QALYs and three important types of things that are wrong with them. The good thing about OALYs is that they point to the importance of quality of life as well as quantity and constitute a noble attempt to provide a quantitative measure of quality. The bad things about QALYs are that they (1) fallaciously value time lived instead of individual lives; (2) take an excessively narrow view of what quality of life might be; and finally and perhaps most importantly (3) they are unjust. There will be space only for the briefest account of the problems with QALYs so I shall say nothing at all about the conception of quality they encapsulate, and concentrate instead on the first and the third of the difficulties with them. But first a word in their favour.

\section{The good of QALYs}

If you or I fall ill, we would rationally want any therapy we were offered to attempt to maximise the QALYs we would expect following therapy, and if rival therapies were available for our illness it would be sensible for us to prefer the therapy which offered the most QALYs. For the individual, QALYs provide a good account of rational preference in health care. For example, for an individual who could not make an informed choice or give informed consent to therapy, say because that patient is a young child, a mental patient, unconscious or demented, then a good principle for those who must decide what to do for the best would be to decide to maximise QALYs for that patient.

However, QALYs are not principally designed to fulfill this role. QALYs are designed as a tool to aid in the distribution of scarce resources between claimants, not as a means of choosing between abundant therapies for one potential recipient. They are a way of establishing priorities in health care and where resources are scarce, priorities do not only mean that highest priorities are catered for first, they mean that lowest priorities will not be met at all. But they also lead to a strange idea of just what top priorities in health care may be, and this leads me to the first major problem about QALYs. 


\section{QALYs maximise units of lifetime}

QALYs are offered as a measure of the benefit to be gained from treatment. They stipulate that benefit is proportional to the number of QALYs produced by the treatment. As one writer on the subject of QALYs has aptly remarked, 'QALYs belong to the realm of maximising' [3]. This means simply the more QALYs the more benefit. This has three related consequences that constitute important drawbacks to the respectability of QALYs.

The first is that if, as Alan Williams [4] has said, each QALY is of equal value no matter who gets it, then two sorts of rather different consequences follow. The first is that it is a matter of indifference if one person gets thirty or thirty get one each; and if a treatment will give one person thirty-one more quality adjusted years of life expectancy and the same resources can purchase 5 years each for 6 individuals, then the resources should go to the one, even if that means that the other 6 die as a consequence!

The second consequence, that so far as I am aware, Williams and other OALY advocates have never addressed, is that if maximising QALYs is the objective of health care, then you can do this either by extending the lives of existing people or by producing new oncs, by bringing extra pcoplc into the world [5]. Now with other things being equal, extra babies will have long life expectancy, and so you get more QALYs by abandoning birth control and providing incentives to procreation than you get by most life saving treatments.

Finally there is the problem of insignificant remission. Suppose the same resources could purchase a treatment which would prolong the lives of 121000 people by one month or could alternatively give each of 1000 people 10 more years of life (quality equal in all cases). If one unit of lifespan is of equal value no matter who gets it, then QALYs dictate that you allocate the resources so as to provide 121000 life months.

The first and the second consequences of the life units dimension of QALYs raise issues of fairness and it is to a consideration of these which we must now turn.

\section{QALYs and justice}

The use of QALYs as the guiding principle for the allocation of scarce health care resources will mean inevitably that such resources are distributed in 3 sorts of unjust ways. By that I mean that they will be distributed in ways which will de facto discriminate unfairly against some sorts of people. I cannot hope in this short paper to do justice to justice. We are talking, it must be remembered, not about justice in the abstract but about what principles may defensibly be used to allocate public resources - in this case health care resources, I am assuming that in this context, whatever else justice requires it presupposes a principle of equality which requires that something like equal concern, respect and protection be shown to all citizens in the distribution of those public resources which affect citizens' chances of survival and other fundamental interests. That it would, in short, be unjust to 
distribute life-saving resources in a way which in effect valued the lives of some sorts of citizens more highly than others [6].

Now QALYs cncapsulatc an ethic which would have just this effect in at least two important ways [7].

It will usually be more QALY-efficient to concentrate on areas of medical care which will inevitably generate more QALYs and equally to channel resources away from areas which can of their very nature produce only a limited quantity of QALYs. Saving the lives of younger people will always be likely to produce more QALYs than saving the lives of older people. This is because any calculation of the life-years generated for a particular patient by a particular therapy must be based on the life expectancy of that patient after treatment. The older a patient is when treated, the fewer life-years that can be achieved by therapy. Hence QALYs will have what I have called an 'ageist' bias [8] and will inevitably discriminate against the old. Neonatal care and paediatrics will inevitably be more QALY-efficient than will geriatric medicine or terminal care.

The prioritising dimension of QALYs has another discriminatory effect, this time against the poor. Since a high priority activity is one where the cost per QALY is low and a low priority activity is one in which the cost per QALY is high, QALYs rcquirc us to choose both the cheapest treatment and the illness which is cheapest to treat. This has a number of consequences. In the first place it may lead us to ignore diseases or conditions which are expensive to treat, even though as experience is gained the cost might well be reduced, even though much might be learned in the process, and even if, though the cost of treating each individual is high, relatively few people are affected and so the total cost is small.

The effect of this might be to deny people afflicted with certain conditions that are expensive to treat any effective help from a health service. Now at first sight it might seem not only sensible but also consistent with justice to ensure that as much benefit as possible is obtained from public resources. But Ronald Dworkin. for example, is surely right when he equates political equality with the idea that "weaker members of a political community are entitled to the same concern and respect of their government as the more powerful members have secured for themselves' [9]. Now the poor of course are certainly a example of the weak that Dworkin had in mind, and one central requirement of justice is to ensure that they have equal access to adequate health care. But this requirement would be illusory if it were to be stipulated that their access to hcalth carc was conditional upon their not suffering from anything expensive to treat.

We have seen then that QALYs will inevitably lead to the poor and the old being consistently discriminated against in the allocation of health care resources. I have suggested that a state cannot do this in the allocation of public resources and maintain a claim to treat all its citizens as equals or deal justly between them. Now maybe obtaining maximum benefit from health resources is more important than distributing them justly, and maybe this is how a state ought to distribute its health care resources. I shall not enter very far into this debate, for I will be content if I have shown that QALYs require substantial additional arguments to sustain them. I would, however, like to conclude by saying a little more about the wrong that is 
done an individual when they lose out in the allocation of scarce health care resources, and in doing so say a little more about what goes into the 'quality' part of the quality of life.

\section{All lives are of equal value}

In a stimulating and thoughtful discussion of OALYs, John Broome [10] says some very interesting things about the value of life and about fairness. He takes as his point of departure some remarks of mine in an earlier discussion of QALYs, and the differences between us over these issues highlights some of the crucial background assumptions of the QALY debate.

Broome suggests that I do not 'properly separate the consideration of fairness from the consideration of total good' and that consequently I make 'several false statements'. Broome then quotes from my earlier manuscript and identifies the mistakes. I will re-present the passage with my supposed mistakes numbered by Broome.

(1) All people who wish to go on living, however uncomfortable their existence may be, however many friends or relations they have, however long or short their lives may be expected to be, have each of them something that is of equal value to themselves - call it the rest of their lives. (2) Each is equally wronged if their lives are cut needlessly short, that is, if their lives are not prolonged when they want them to be and when they could be. Whatever the rest of our lives might be expected to be like, so long as we want our lives to continue, then (3) we each suffer the same misfortune, and (4) are wronged in the same way when that wish is deliberately frustrated by others [11].

Briefly Broome thinks that statement (4) is true in one sense and the other 3 are all 'falsehoods' [11]. It is instructive to look more closely at just why Broome thinks these statements false.

Take (1) first. The notion of the value to a person of some object is a fairly flexible one. One possible sense is how much the person wants it. But amongst people who want their lives to continue, some want that more than others. Another possible sense is how valuable that person believes the object to be. But amongst people who want their lives to continue, some think their lives more valuable than others think theirs. So in neither of these senses is the value to a person of the rest of her life the same for everybody.,..

Next (2) - it is debatable what wrong or wrongs are done a person in cutting her life needlessly short. Amongst the wrongs done her may be an injustice and, possibly, this may be an equal wrong for everybody. But also amongst the wrongs is the wrong of depriving her of good. The good she is deprived of is the difference between how good her life would have been had she continued to live and how good it is, being cut needlessly short. This difference is not the same for everybody. So not cvcrybody is cqually wronged by having their lives cut needlessly short.

Finally (3) - Some people suffer a greater loss of good than others if their wish 
to live is frustrated. I have just said that. So they suffer a greater misfortune. [13].

Broome charitably wonders 'what leads Harris to advance these falsehoods'? He concludes that what I wish to say is something like "everyone has an equal claim to life, so they suffer an equal unfairness if their claim is overridden' but that because I speak of 'value, wrong and misfortune, all things that... have to do with good' I must be in the grip 'of the utilitarian view that what is fair must be determined by what is good' [14].

It is perhaps my fault that the passage in which Broome finds so many errors is insufficiently cautious. What I was trying to do was explicate the basis of everyone's equal claim to life, and hence the wrong done to them if their claim is overridden. That is to say, the wrong done over and above the wrong of injustice or unfairness. However, this notwithstanding, I don't think any of the claims I made are sufficiently clear as to amount to falsehoods (a worse error perhaps); but if they are made clearer $I$ think they are defensible to an extent that Broome's objections are not. And the defence carries the debate about QALYs a little further.

When I claimed that all those who want to live have something of equal value - namely the rest of their lives - I meant by the term 'value' simply that such people value their lives in an ultimate sense. That is, the sense in which they want their lives to continue and are unwilling to accept any trade-offs, unwilling, for example, to accept that it is legitimate to sacrifice their lives for the sake of third parties. It is simply the claim that a particular person is a person, is morally important, shares the same moral and political status as all other persons, however devoid of good in Broome's senses, and however undistinguished, her life may be. Now one can value one's life in this sense while recognising that it may not be as valuable as that of other people in other senses, including all those that Broome mentions. One can then value it in this sense on a par with the lives of all and any others, while at the same time recognising it is not as full of goods as theirs are, and while wishing that it was.

George Teeling Smith [15], in explicating the theory behind QALYs, makes a claim that could lead to problems analogous to those which characterise Broome's position. He suggests that given the choice, a person would prefer a shorter healthier life to a longer period of survival in a state of severe discomfort or disability'. This supposed truth is sometimes used by defenders of QALYs as a way of suggesting that those who accept it are somehow committed to using QALYs as the right method of resource allocation. For QALYs, it is suggested, are the formalised expression of this preference. But whereas from the fact that given the choice a person would prefer a shorter healthier life to a longer one of severe discomfort, it follows that the best treatment for that person is the one yielding the most QALYs, it does not follow that treatments yielding the most QALYs are preferable where different people are to receive the treatments. For while I might prefer one year of full remission to 3 years of discomfort for myself, where the choice is alternative between one year of full remission for you or three years discomfort for me, it does not follow that I am somehow committed to the judgement that you ought to be saved rather than me.

I can without error or inconsistency recognise that your life is more valuable in 
the sense of more full of all the things that make a life good (and indeed wish fervently that my life were like yours in those respects), without being committed to the view that where your life is in the balance with mine, yours is more valuable in the sense of more worth saving. I wish my life was more like yours, but since it isn't, I want it to continue as much as I would if it were more like yours. I do not have to believe, as Broome apparently does, that all those whose lives are better than mine are more valuable as persons, more worth saving, and that public resources might defensibly be allocated to saving their lives before they are allocated to saving mine.

Now Broome thinks the value of life and hence the wrong done when life is prematurely ended, just is 'the difference between how good her life would have been had she continued and how good it is, being cut needlessly short' [16]. Indeed, he thinks that if 'a person's life is extended...the good done her is no more nor less than the extra good she enjoys during the extended lifetime' [17]. Unlike Broome, I don't think the rightness or wrongness of positions such as his and mine can be a matter of straightforward falsehood. The wrongness of his position lies not in its telling falsehoods but in its implausibility and the sophistical arguments to which it leads.

Shakespeare's conspirators in his Julius Caesar argue themselves into the rectitude of murdering Ceasar by thinking that 'he that cuts off twenty years of life cuts off so many years of fearing death' and Brutus is so pleased with this suggestion that he responds: 'Grant that, and then is death a benefit; So are we Ceasar's friends, that have abridg'd His time of fearing death' [18]. Now the corollary of Broome's argument is nicely analogous. The wrong done someone when their life is cut short is no more nor less than the deprivation of the good of that extra lifetime. So that where someone's prognosis for quality of life is so poor that there is no good in their future life, then no wrong is done them if they are killed even against their will.

There seems to be for Broome no residual wrong in frustrating the desire to live of a moral being unless of course it is unfair to do so, but since fairness has to do with 'mediating between the claims of different people' [19], there will be no wrong in killing such a person in the absence of competing claims. Whereas the position I was trying to articulate locates the wrongness of ending the life of a person who wishes her life to continue principally in the frustration of that desire.

Since, according to Broome, 'not everybody is equally wronged by having their lives needlessly cut short' [20], the wrongness of murder varies with the quality of life of the victim, and killing paupers is (other things being equal) worse than killing princes; and killing those with more QALYs is worse than killing those with fewer.

And this of course is the final problem with QALYs.

\section{References}

1 I have made these points in more detail in my 'QALYfying the Value of Life,' Journal of Medical Ethics, September 1987 and 'More and Better Justice' in Sue Mendus and Martin Bell (Eds.), Philosophy and Medical Welfare, C.U.P. in press. 
2 Williams, A., The value of QALYs, Health and Social Service Journal, July (1985) 3.

3 Broome, J., Good, Fairness and QALYs. Typescript 1986, to appear in Mendus and Bell, op cit.

4 Williams A., Op Cit. p. 5.

5 This point is discussed by both Broome and I (see notes 1 and 3 above).

6 For an elaboration of this point see my More \& Better Justice, op cit.

7 For other ways see my 'QALYfying The Value of Life'. Op cit,

8 Ibid.

9 Dworkin, R., Taking Rights Seriously, Duckworth, London 1977. p. 198.

10 Broome, J., op cit.

11 This quotation is taken from the typscript of lecture notes I prepared for a talk given in 1985. The context from which I took the ideas is my The Value of Life, Routledge and Kegan Paul, London 1985, p. 89.

12 Broome, J., op cit. p. 4.

13 Ibid, pp. 3, 4.

14 Ibid.

15 Smith, G.T., The Measurement of Health, Office of Health Economics. London 1985. p. 16.

16 Broome. J., op cit. pp. 3, 4.

17 Ibid. p. 13.

18 Julius Caesar. Act III. Scene 1.

19 Broome. J., op cit. p. 4.

20 Ibid. p. 7. 